\title{
Internet-based instruction of the principles of base rate and prediction: A demonstration project
}

\author{
SOREN SVANUM, SHEN HSING A. CHEN, and SCOTT BUBLITZ \\ Indiana University-Purdue University, Indianapolis, Indiana
}

\begin{abstract}
An Internet-based instructional module was developed using Netscape 2.0 as the graphical interface. The content concerned Bayesian probabilities and expected outcomes associated with the use of urine drug screens. JavaScript enabled interactive calculations of outcome probabilities given a selected set of parameters, and AppleScript and Claris Filemaker Pro monitored and recorded student activity and progress. The module was initially used in an undergraduate class on alcohol and drugs and subsequently evaluated on a sample of undergraduates. Student response was favorable, and student learning assessed by performance on an exam was good. Students who described themselves as not computer literate did not particularly enjoy the experience, although they performed as well as others on the test. The success of this demonstration project has led to more ambitious implementations, particularly those that monitor student activities and provide intelligent feedback.
\end{abstract}

Social philosophers and pundits predict that computer networking, specifically the Internet (Kehoe, 1993), will have revolutionary influence and drastically alter the fabric of everyday life. One potential area of change that has considerable promise involves the use of the Internet as an educational tool (Kelley-Milburn \& Milburn, 1995), particularly as one form of computer-assisted instruction. In comparison with traditional methods (e.g., textbooks) or other computer-based methods (e.g., instructional CDs), Internet-based activities can employ a distinct pattern of characteristics that include, first, the ability to be used remotely. If the user has Internet access, either at home or in the university, materials can be used at any time. Such availability is particularly useful among so-called nontraditional students who often attend nonresidential universities, are employed, or will otherwise benefit from widespread availability. In addition to wide geographic dissemination of material, Bailey and Cotlar (1994) maintained that Internet-based instructional activities might result in more efficient, and more effective, allocation of institutional resources.

Second, Internet-based materials can be interactive and provide performance feedback to the user. The interactive potential is substantial and, for example, traditional divisions between textbook material and study guide can disappear as interactive and intelligent systems of learning can be developed and delivered. In general, interactivity can be defined as the ability of the user to actively participate in the learning situation and have at least some control of the information presented (Petty $\&$ Rosen, 1987). The degree of control can be used to dis-

A version of the learning module described in this article is available for viewing at http://psynt.iupui.edu/detection/drugdetect_main.html. Correspondence should be addressed to S. Svanum, Department of Psychology, Indiana University Purdue University, 402 North Blackford Street, Indianapolis, IN 46202 (e-mail: ssvanum@iupui.edu). tinguish two types of interactive learning models (Carlson \& Falk, 1990). In the "passive-learner model," the instruction flows into a reactive learner who is unable to influence either the content or style of the presentation; in contrast, in the "active-learner model," the learner can influence the instructional systems either through choosing what he/she wants to learn or through deciding how he/she will learn it (Carlson \& Falk, 1990). These passive- and active-learner models involve differing interactions between the learner and the instructional systems, and are within the technical capabilities of Internetbased instruction. Some content (e.g., basic descriptive statistics) may be effectively presented in a passive learner mode, whereas other content (e.g., concepts of prediction under uncertainty) may be most efficiently learned in an active learner mode (Carlson \& Falk, 1990).

Interactive learning components have demonstrable benefits, including increased student interest and enjoyment (Petty \& Rosen, 1987) and more positive learning outcomes. In a study comparing the use of hypertextenabled browsing, an interactive feature that is readily implemented within an Internet environment, with sideby-side comparison by book learners, it was shown that student novices could use hypertext more easily than they could use a book to learn the names of airplanes (Psotka, Kerst, \& Westerman, 1993). The authors concluded that the use of hypertext presents features that enhance learning by representing, linking, and exploring the knowledge studied.

Third, the presentation of materials can employ a familiar interface that is compatible with different computer operating systems. Once a user is familiar with the standard interface, different materials are readily accessed without the need for new learning of the mechanics of presentation. Cross-platform compatibility and the use of a standard interface can reduce the amount of re- 
sources needed to develop and implement instructional software as well as target a larger group of users.

Last, Internet-based instruction can allow for monitoring the extent and pattern of student use and progress. This advantage has tremendous potential, both in terms of monitoring the progress of individual students and in terms of investigating how learners learn. It may be particularly useful in exploring aptitude-treatment interactions (Cronbach \& Snow, 1977) in learning, an area of research that has been difficult to investigate prior to the many technological changes reflected in the Internet. Cohen, Tsai, and Chechile (1995) demonstrated the use of a system for tracing and recording how students used educational technology as a nonintrusive, formative evaluation model for generative learning environments. The Internet allows such technology to be implemented with relative ease and gives impetus to investigations of the kinds of cognitive and behavioral events that take place while students interact with educational software.

The purpose of this project was to develop and evaluate an Internet-based instructional module that would implement the potential strengths outlined above. The concept chosen was the influence of base rate on prediction, a concept that has been difficult to teach in past attempts, particularly to psychology undergraduates, who often become inordinately apprehensive with arithmetic content. Furthermore, although this approach to understanding the concepts and mechanics of prediction has been well understood for a long time (e.g., Meehl \& Rosen, 1955), it has not been well integrated within the methods taught at the undergraduate or graduate level (Kleinmuntz, 1991).

Within a course on alcohol, alcoholism, and drug abuse, the topic of the use of urine drug screens was covered. In many local communities, the use of urine drug screens among high school students to encourage drug abstinence and identify users is a controversial and, at times, hotly debated topic. Although there are many perspectives (e.g., political, legal) that may influence and shape opinion in this matter, psychology can provide technical understanding and a means to quantify decision making that is based upon measures that necessarily have a degree of unreliability. The module, then, introduced students to the use of urine analysis to detect drug use, to the basic principles of decision analysis, and to the influence of base rate on prediction. In the present study, learning outcome was assessed with a multiple-choice and fill-in exam. A questionnaire was included to investigate the attitudes of the students toward computer use and to ascertain whether such attitudes were related to performance on learning the material presented.

\section{METHOD}

\section{Subjects}

Nine male and 8 female students were recruited from a university research subject pool. The majority $(n=13)$ were advanced undergraduates or graduate students taking undergraduate classes. All agreed to attend two l-h sessions 1 week apart. Both sessions were held in a university computer laboratory where all worksta- tions were connected to the Internet. The subjects were run in two groups of 9 and 8 students each, and all were told to anticipate an examination of module content at the end of the second session. A $\$ 15$ lottery-ticket package given to the person with the highest score on the content exam served as incentive.

\section{Materials}

The course materials were developed and published on an Apple Macintosh PowerPC 8500 running WebStar (StarNine, 1995), an Internet server software package. AppleScript (Goodman, 1994) served as the common gateway interface (CGI), the means to communicate between the Internet protocols and other server functions. Claris Filemaker Pro 3.0 (Claris, 1995) was used as a database; JavaScript (Cornell \& Horstmann, 1996), a browser-based language, enabled computational interaction between the student and Bayes theorem.

The materials were formatted with hypertext markup language (HTML), the standard that is read by such World-Wide Web (WWW) graphical clients as Netscape. Netscape is widely used within our university and, for example, provides the University Library interface to electronic-based resources. Many students are already familiar with Netscape and can quickly focus upon content rather than mechanics of use. The employment of a widely used interface, then, has distinct advantages. To facilitate use, Netscape 2.0 frame structure was employed; an outline of the materials appeared in the right frame $(25 \%)$ and the content appeared in the left frame. Navigational links also appeared at the end of each content page, so users could proceed through the materials using anchors within content pages or with anchors embedded within the right outline frame. Using either method, outline anchors in the right frame changed color as the user navigated through the material.

The initial page establishes the basic problem: "Your 17-year-old son has tested positive for marijuana use, but denies any use. The urine drug test was administered as part of a mass screening of students at his school. The school maintains that these tests are very accurate $(95 \%)$. Should you believe your son or the results of the testing?" Most importantly, the problem is framed probabilistically and the question is best viewed as one of the degree of confidence attached to each possible decision. The following pages present the information necessary to assess these estimates. This introduction also provides an opportunity for students to express an initial opinion on the general question of the use of widespread urine drug screens among high school students. This is accomplished by HTML Forms in combination with an AppleScript that interfaces with e-mail such that responses are forwarded to the professor.

Subsequent pages present such basic principles of urine drug screens as the window of detection (about 3 weeks with marijuana) and issues of expected accuracy and various sources of measurement error. The student is then introduced to the basic terms of prediction as presented in a $2 \times 2$ table. Following this, proportions are calculated that quantify the terms introduced, such as correct positive and false negative. The user is then introduced to the two important qualities of test sensitivity and specificity. Decisions made with tests can be fully described with three parameters: sensitivity, specificity, and the frequency with which the behavior of interest occurs in the sample. Accordingly, the effects of base rate are then introduced, and users learn to discriminate between the question of sensitivity (proportion of users correctly identified) and positive predictive power (proportion of drug-test-positive persons who have used), the question that began the module. Overall test accuracy was assumed to be .95 ; marijuana-use base rate among 17year-olds was taken from the U.S. Household Survey data of 1993 (National Institute on Drug Abuse, 1995), which estimated a 1-month prevalence use of .05 . Using these values, the user discovers that the probability that his/her son used drugs is not 9.5 in 10 , but 1 in 2 .

The materials then provide an interactive demonstration. Input variables are the sample size, estimated overall test accuracy, and the estimated base rate of the problem in the population. The user 
indicates these values and clicks on "calculate"; the $2 \times 2$ table results are displayed along with positive and negative predictive power. Calculations are browser based, performed with JavaScript, and can be done repeatedly for a range of values of base rate, test accuracy, and sample size. Sample size is not a critical value, but added for convenience of use. Because JavaScript is browser based, these calculations are done on the user's computer, lessening server load and distributing the workload over the network. Following this, students can access a set of multiple-choice questions covering the content presented.

Upon entering the module, each student is required to provide a last name and a preassigned password. With each page request, this user information is passed from the browser to the server, then recorded in a student record data base. Responses to test items can be scored, and such a data base can readily provide a summary of each student's activity and progress. Activity between the browser and server is enabled by a set of procedures programmed in AppleScript, and the data are recorded in a Filemaker Pro database. This database is "scriptable" and will respond to requests made in AppleScript to insert, delete, and update selected records.

These materials were initially used in an undergraduate course on alcohol, alcoholism, and drug abuse. WWW materials were accessed during class and presented through an overhead projector. Lecture material elaborated on module content. Following class, more than one-half of the students accessed the material remotely, many from home-based computers. One student developed the theme with great interest and was subsequently active in a local high school discussion of the pros and cons of widespread use of urine drug screens.

\section{Procedure}

Subjects completed a survey at the end of the first and second sessions. Fifteen questions with a Likert-type, 5-point rating scale ranging from strongly disagree (1) to strangly agree (5) inquired about the effectiveness of the mechanics of presentation, the student's impressions of the effectiveness of these Web-based pedagogical tools, and the student's general satisfaction with the pages. An additional purpose of this evaluation was to determine that the movement through the pages was effectively recorded in the database as small groups of students accessed the materials in a somewhat simultaneous fashion. To accomplish this, all students were assigned a unique user name and password. Data-base activity was observed on the server, and teaching assistants observed student activity in the computer laboratory.

\section{RESULTS}

In responses to survey items concerning their familiarity with computers, all but 1 student reported weekly or more frequent use of a computer, and all but 4 students reported that they had a computer at home. Most $(n=12)$ considered themselves computer literate, and 7 indicated that they use the Internet with some frequency. The two groups of students spent approximately $1 \mathrm{~h}$ and 30 min involved with the learning module. Responses to survey questions indicated that students had few, if any, problems with the mechanics of use. Table 1 summarizes the 15 survey items on the presentation, impressions, and general satisfaction with the Web-page module.

For example, pages were seen as easy to read $(M=$ $4.1)$, and students expressed disagreement $(M=2.2)$ with a statement that the Web-page layout was confusing, or that it was difficult to keep track of movement through the pages $(M=2.4)$. Responses to items that concerned mechanics of use were equally positive among those 5 students who did not describe themselves as computer literate.

As for pedagogy, students reported that they enjoyed using the module to learn concepts of prediction $(M=$ 3.5 ), and that they found the interactive demonstration useful $(M=3.9)$ in helping them to understand the concepts of base rate and prediction. Most $(M=3.5)$ indicated that they would like to use similar modules covering other material. Performance on the moderately difficult examination averaged $75 \%$ correct, with the highest score being $86 \%$ correct. Such performance does represent an adequate understanding of material. Those who described themselves as computer illiterate $(n=5)$ did as well on the examination as other students who described

Table 1

Mean, Percent Agree, and Standard Deviation of Survey Items

\begin{tabular}{lrrr}
\hline \multicolumn{1}{c}{ Item } & Mean* & Percent Agree† \\
\hline & Presentation & & $S D$ \\
Information was presented clearly & & 3.9 & 82 \\
Layout was easy to follow & 4.1 & 82 & 18 \\
Had difficulty keeping track of materials presented & 2.4 & 0.6 \\
Base rate presentation and layout was confusing & 2.2 & 18 \\
Text on web page module was easy to read & 4.1 & 94 \\
Found materials visually attractive & 3.9 & 77 & 0.7 \\
\end{tabular}

Had no problems working through the module

Materials were too long and dry

Impressions

Module helped to clarify base rate concepts

More interesting than regular text

Interactive layout were useful in understanding concepts

General Satisfaction

Would use module again for review

Would like to use web page module with other concepts

Do not like Internet-based materials

Enjoyed using web page module for learning base rates concepts

$$
\begin{aligned}
& 3.4 \\
& 2.8 \\
& 3.3 \\
& 3.2
\end{aligned}
$$

3.9
${ }^{*} n=17 . \quad+$ Percent agree $=[$ agree $(4)+$ strongly agree $(5)] / 17 \times 100$. 
themselves as computer literate $[t(15)=-0.11, p=$ n.s.]. However, students who saw themselves as computer illiterate clearly indicated that they would not like to use similar materials for other courses [3.9 vs. 2.6, $t(15)=4.7, p<.01]$ and that they did not enjoy the computer-based experience on prediction [3.9 vs. $2.6, t(15)$ $=3.9, p<.01]$, again in comparison with their more computer-literate peers.

\section{DISCUSSION}

The present study describes the implementation of several Internet components into an instructional module, which was then evaluated by a sample of university students. Students reported few problems with the mechanics of the module, and results suggested that, on average, students were favorable toward computer-based learning material. A subset of students reported being less inclined toward computer use and less enthusiastic about using computer-based materials again. On the basis of the results of an examination of module content, students appeared to acquire a good understanding of the principles presented. Future research might systematically assess the degree to which learning with computer-based instruction is comparable to and different from other learning methods. In terms of learning, it might be noted, the subset of students who described themselves as not computer inclined demonstrated a degree of learning comparable to that of their more computer-literate peers.

A powerful feature of the server/browser activity on the Internet is the ability to monitor activity. This can provide a feedback loop to the instructor whereby individuals who experience difficulty can be identified, allowing the instructor to evaluate overall module effectiveness at the group level. By providing an interactive, well-controlled learning environment that can support rigorous evaluation (Shute \& Regian, 1993), extensions of this structure can provide the basis for investigating learning styles. From a technical perspective, as students used the pages, progress was recorded in the server database, and at the end of each session, tallies were present for each student, broken down by each module page accessed. The computer overhead for this activity was, however, noticeable at the server end and among assistants monitoring browser activity in the laboratory. Students did not comment negatively about what seemed, to the assistants, to be a somewhat sluggish Internet response. Using a more powerful server and programming the database interface in a more efficient way will be necessary in fully operational projects. The procedures associated with open database connectivity, a recently developed component of several different computer operating systems, may provide a more effective interface.
These results, then, indicated that Internet-based instructional technology could be very adaptable to university instruction, and that it has the potential to track student activity and, consequently, student learning. More ambitious projects are under way; these will track student progress in greater detail, provide assessment items as an integral part of the module, and provide suggested module sources of remediation when progress is inadequate. This ability to provide intelligent feedback has substantial promise. In addition, the generally favorable student response suggests receptivity to these Internetbased approaches.

\section{REFERENCES}

Bailey, E. K., \& Cotlar, M. (1994). Teaching via the Internet. Communication Education, 43, 184-193.

CARLSON, H. L., \& FalK, D. R. (1990). Interactive learning models using videodiscs in college and inservice instruction. Computers in Human Services, 7 (3-4), 277-293.

Claris Corporation (1995). File Maker Pro (3.0): Users guide. Santa Clara, CA: Author.

Cohen, S., Tsai, F., \& Chechile, R. (1995). A model for assessing student interaction with educational software. Behavior Research Methods, Instruments, \& Computers, 27, 251-256.

Cornell, G., \& Horstmann, C. S. (1996). Core Java. Englewood Cliffs, NJ: Prentice-Hall.

Cronbach, L. J., \& SNow, R. E. (1977). Aptitudes and instructional methods: A handbook for research on interactions. New York: Irvington Publishers.

Goodman, D. (1994). Danny Goodman's AppleScript handbook (2nd ed.). New York: Random House.

KEHOE, B. P. (1993). Zen and the art of the Internet: A beginner's guide. Englewood Cliffs, NJ: Prentice-Hall.

Kelley-Milburn, D., \& Milburn, M. (1995). Cyberpsych: Resources for psychologists on the Internet. Psychological Science, 6, 203-211.

KLEINMUNTZ, D. N. (1991). Decision making for professional decision makers. Psychological Science, 2, 138-141.

Meenl, P. E., \& Rosen, A. (1955). Antecedent probability and the efficiency of psychometric signs, patterns, or cutting scores. Psychological Bulletin, 52, 194-216.

NATIONAL InSTITUTE ON DRUG ABUSE (1995). National household survey on drug abuse: Main findings 1993 (DHHS Publication No. SMA 95-3020). Washington, DC: U.S. Government Printing Office.

PetTy, L. C., \& Rosen, E. F. (1987). Computer-based interactive video systems. Behavior Research Methods, Instruments, \& Computers, 19, 160-166.

Psotka, J., Kerst, S., \& Westerman, T. (1993). The use of hypertext and sensory-level supports for visual learning of aircraft names and shapes. Behavior Research Methods, Instruments, \& Computers, 25, 168-172.

Shute, V. J., \& Regian, J. W. (1993). Principles for evaluating intelligent tutoring systems. Journal of Artificial Intelligence \& Education, 4, 245-271.

StARNINE TeChNologies (1995). WebStar: User's guide. Berkeley, CA: Author.

(Manuscript received October 3, 1996; revision accepted for publication January 10, 1997.) 